\title{
Identification of Field Resistance to Bacterial Leaf Spot Disease of Anthurium under Natural Epiphytotics in Trinidad
}

\author{
Annelle W.B. Holder, Winston Elibox, Christopher Avey, \\ and Pathmanathan Umaharan ${ }^{1}$ \\ Department of Life Sciences, Faculty of Science and Technology, The \\ University of the West Indies, College Road, St. Augustine, Republic of \\ Trinidad and Tobago
}

Additional index words. Acidovorax anthurii, disease tolerance, foliar resistance, sick plot, systemic resistance, disease screening, resistance breeding

\begin{abstract}
Six anthurium cultivars, grown widely in Trinidad were evaluated for field resistance to Acidovorax anthurii, the causal agent of bacterial leaf spot disease (BLS), in a disease nursery to determine whether resistance/tolerance to BLS can be reliably assessed in field studies. The experiment was arranged in a randomized complete block design with four replications and with 25 plants per replicate per cultivar. Data on time to first symptoms, cumulative number of diseased leaves and cumulative number of dead plants per replicate per cultivar was recorded on a monthly basis over a 12-month period. Cubic polynomials were fitted for cumulative number of diseased leaves and cumulative number of dead plants per replicate for each cultivar and the largest slopes obtained during the exponential phase were investigated for the two parameters. The validity of resistance measures were assessed by correlating to field resistance assessed from a farm survey in another study. Time to first symptoms was found to be independent of the cultivar's BLS resistance score. Cultivar differences for cumulative number of diseased leaves and dead plants were significant $(P<0.001)$ at 12 months after planting (MAP), with a strong correlation between them (Pearson's $r=0.84$, Spearman's $r=0.89, P<$ 0.05). The largest rates of disease progression in leaves or disease progression measured as plant death over time were higher in the susceptible anthurium cultivars compared with the moderately resistant ones. Cumulative number of diseased leaves at 12 MAP was more discriminatory among cultivars and showed a larger correlation with field resistance scores obtained from the island-wide survey than cumulative number of dead plants and is therefore proposed as the reliable measure for assessing field resistance to BLS. The use of this method for breeding anthurium for BLS resistance is discussed.
\end{abstract}

Bacterial leaf spot disease of anthurium (Anthurium andraeanum L.) caused by $A$. anthurii (Gardan et al., 2000) was first reported in the French West Indies (Prior and Rott, 1989; Prior and Sunder, 1987; Prior et al., 1985) and later in Trinidad (Dilbar, 1992; Holder et al., 2015; Saddler et al., 1995). It is regarded as one of the major contributors to the demise of the anthurium industry in the Caribbean region (Holder et al., 2015; Saddler et al., 1995).

The pathogen enters the vascular system of anthurium leaves via natural openings (stomata and hydathodes) or wounds (Prior et al., 1985). Early foliar symptoms of BLS

Received for publication 6 Sept. 2016. Accepted for publication 17 Oct. 2016.

We thank the staff of the Department of Life Sciences of the University of the West Indies at St. Augustine for their assistance in executing this study. We also thank the management and staff of Kairi Blooms Farm for providing the facilities for the field trial.

${ }^{1}$ Corresponding author. E-mail: pathmanathan. umaharan@sta.uwi.edu. are characterized by small, angular, greasy spots on the lower surface of leaves near veins and leaf margins (Prior et al., 1985). Lesions develop rapidly resulting in large, black necrotic spots which become grayblack on older leaves and also deform the infected leaves (Prior et al., 1985). Necrotic spots are also surrounded by greasy margins and narrow, bright chlorotic halos (Dilbar and Gosine, 2003; Prior et al., 1985). Foliar infections may progress into veins causing a soft rot and eventual abscission of the petiole. Infections can become systemic, resulting in the general yellowing of the entire leaf lamina and typical black, necrotic lesions progressing from the leaf petioles into the major veins (Prior and Rott, 1989). Systemic infections lead to eventual plant death (Prior et al., 1985).

The Caribbean anthurium industry is based primarily on cultivars imported from the Netherlands and several of these are susceptible to BLS. However, no study has been performed to show the differences in progression of disease symptoms and rates of eventual death in anthurium cultivars under natural epiphytotics in the humid tropics. An understanding of disease progression will aid in the development of appropriate management strategies to combat the adverse effects of BLS on the anthurium industry. As such, the objective of the study was to identify potential sources of resistance to $A$. anthurii under natural epiphytotics and understand disease progression among six anthurium genotypes grown by anthurium farmers in Trinidad.

\section{Materials and Methods}

The experiment was conducted in a BLS disease nursery $(0.9 \mathrm{~m} \times 2.8 \mathrm{~m})$ at a commercial farm, Kairi Blooms Farm, located in Carapo, Trinidad, where an earlier epidemic had resulted in the complete death of a susceptible cultivar, Safari. Two-year-old hardened plants of six anthurium cultivars viz. Acropolis, Fantasia, Lambada, Pistache, President, and Sonate obtained through tissue culture and containing five leaves each were used in this study. The experiment was arranged in a randomized complete block design with four replications and with 25 plants per replicate per cultivar. Plants were grown at a spacing of 30 to $40 \mathrm{~cm} \times 30$ to $40 \mathrm{~cm}$ on raised, freely draining beds $(22.9 \mathrm{~m} \times 1.2 \mathrm{~m})$ of coconut husk. The beds were fertilized with either triple superphosphate (Chemos GmBH, Regenstauf, Germany) or $12 \mathrm{~N}-11 \mathrm{P}-13 \mathrm{~K}$ (Norsk Hydro Olje AB, Nybro, Sweden) every month at a rate of $0.45 \mathrm{~kg}$ per bed. The plants were irrigated once daily for $15 \mathrm{~min}$ by overhead sprinkler irrigation. Standard sanitation practices were followed.

On a monthly basis, individual plants per replicate per cultivar were examined for typical BLS symptoms and data on MAP to first symptoms per plant, number of diseased leaves per plant, and number of dead plants per replicate per cultivar were recorded over a 12-month period. All diseased leaves and dead plants were removed on a weekly basis, as per recommended disease management procedures using scalpels that were sterilized by dipping in $70 \%$ ethanol. Bacterial cultures were isolated from all dead plants and a random sample of at most five diseased leaves per cultivar per month. Bacterial isolates were pathogenic and showed typical BLS symptoms on stage-4 (hardened but with a glossy leaf surface) detached leaves of the susceptible anthurium cultivar, Safari. The inoculation method involved injecting $1 \mathrm{~mL}$ of the bacterial suspension $\left(5 \times 10^{8} \mathrm{cfu} / \mathrm{mL}\right)$ into the leaf mesophyll near the midrib (Gardan et al., 2000) followed by incubation in clear polythene bags containing moist tissue paper for $7 \mathrm{~d}$.

Line graphs were drawn to show the mean cumulative number of diseased leaves and number of dead plants per replicate per cultivar. A cubic polynomial equation was fitted for cumulative number of diseased leaves and dead plants per replicate per cultivar over the 12-month period and from each equation, the largest slope and the MAP that the largest slope occurred were calculated. Generalized linear model analysis of variance (NCSS, 2007) was used to determine the significance 
of cultivar mean differences per replicate for MAP to first symptoms; cumulative number of diseased leaves, dead plants after the 12-month period; and largest slope and MAP that the largest slope occurred for cumulative number of diseased leaves and dead plants over the 12-month period. Where cultivar differences were significant, a least significant difference, $\mathrm{a} \mathrm{CV}_{\text {within }}$ (square root of error mean square/general mean), and a $\mathrm{CV}_{\text {between }}$ (SD between the mean values for the cultivars/general mean) were calculated. Pearson's production moment and Spearman's rank correlations (NCSS, 2007) were performed to determine the associations among the parameters and their associations with field rankings obtained for the same cultivars through a national farm survey conducted in 2014 (Holder et al., 2015).

\section{Results}

Diseased leaves. Foliar symptoms of BLS were first observed at $1 \mathrm{MAP}$ on one leaf of one plant of anthurium cultivar Acropolis
(Fig. 1). Three other cultivars, viz., Lambada, President, and Sonate showed foliar symptoms of BLS at 2 MAP, whereas cultivars, Pistache and Fantasia showed initial foliar symptoms at 5 and $7 \mathrm{MAP}$, respectively. However, cultivar differences for mean MAP to first symptoms were not significant $(P>$ 0.05) (Table 1). Cultivar differences for cumulative number of diseased leaves per replicate at 12 MAP were highly significant $(P<$ $0.001)$. At that time, cumulative number of diseased leaves per replicate had reached a plateau for all cultivars (Fig. 1). 'Lambada' had the most cumulative diseased leaves per replicate (74.5), whereas 'Acropolis' had the least (7.3) (Table 1). Tukey-Kramer multiple comparison test placed the anthurium cultivars into three groups based on per replicate mean cumulative number of diseased leaves with 'Acropolis' and 'Fantasia' (9.2 leaves); 'Sonate' and 'Pistache' (34.7 leaves); and 'President' and 'Lambada' (69.7 leaves) grouping separately.

When cubic polynomial equations were fitted for per replicate mean cumulative number

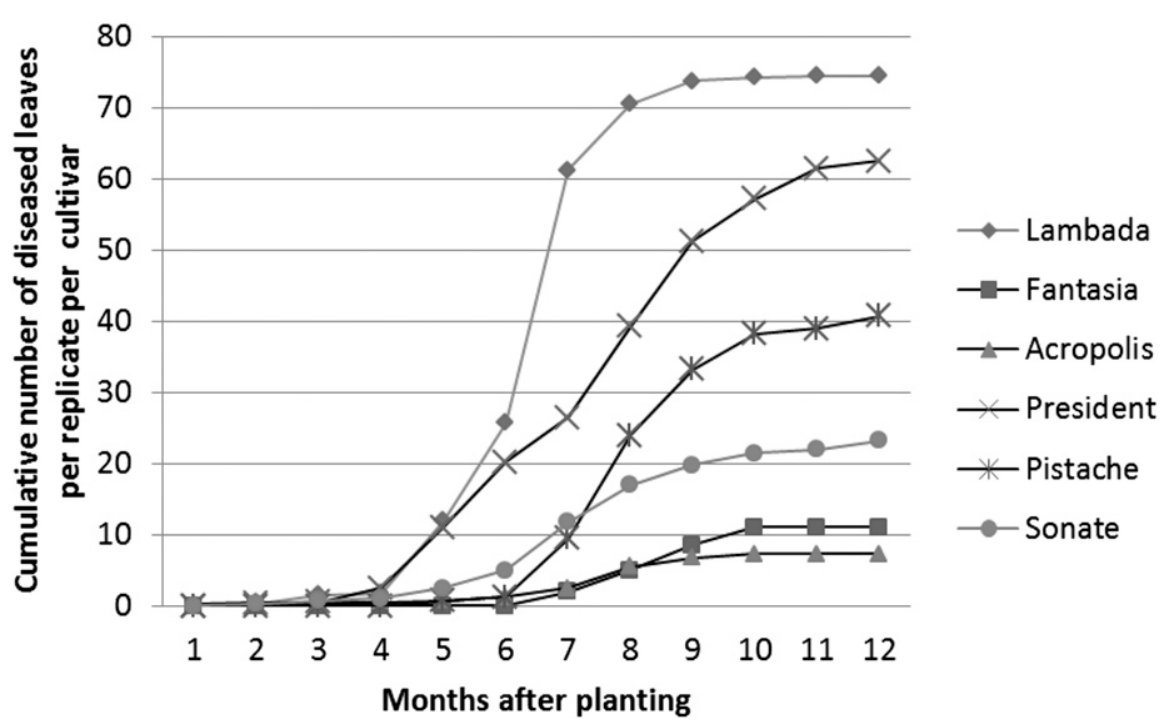

Fig. 1. Cumulative number of diseased leaves per replicate for six anthurium cultivars observed under field conditions in a bacterial leaf spot disease nursery over a period of 12 months.

of diseased leaves for the cultivars over the 12month period, the $R^{2}$ values were large ( 0.95 to 1.00) (Table 1). The six anthurium cultivars showed their largest slopes from 6.3 to 8.0 MAP (mean of 7.2 MAP) and cultivar differences for MAP when the largest slopes were obtained were significant $(P<0.05)$. Cultivar differences for largest slope were highly significant $(P<$ 0.001 ) with 'Lambada' having the largest value (15.76), followed by 'President' (10.11), and with 'Acropolis' (1.35) and 'Fantasia' (2.07) having the smallest values (Table 1). The largest slope for 'Lambada' was more than 11-fold that for 'Acropolis'. Tukey-Kramer multiple comparison test placed the anthurium cultivars into four groups based on largest slopes for mean cumulative number of diseased leaves per replicate with 'Acropolis' and 'Fantasia' (1.71); 'Sonate' (4.08); 'Pistache' and 'President' (8.82); and 'Lambada' (15.76) grouping separately.

Plant death. Among the anthurium cultivars, plant death due to BLS was first observed in 'Lambada' and 'Sonate' at 2 MAP, 'Fantasia' at 3 MAP, 'President' at 4 MAP, 'Pistache' at 6 MAP, and 'Acropolis' at 7 MAP (Fig. 2). Cultivar differences for cumulative number of dead plants at 12 MAP (Table 2) were highly significant $(P<0.001)$ and mean cumulative number of dead plants per replicate per cultivar had reached a plateau for all cultivars except Pistache and President (Fig. 2). At that time, 'President' had the most cumulative dead plants (16.0) per replicate while 'Acropolis' had the least (1.8) with a cultivar mean of 11.0 (Table 2). Tukey-Kramer multiple comparison test placed the anthurium cultivars into two groups based on per replicate mean cumulative number of dead plants with 'Acropolis' and 'Fantasia' (3.2 plants) in group one, and 'Sonate', 'Pistache', 'President', and 'Lambada' (15.0 plants) in group two.

When cubic polynomial equations were fitted for per replicate mean cumulative number of dead plants for the cultivars over the 12-month period, the $R^{2}$ values were large $(0.94$ to 0.99$)$. The six anthurium cultivars showed their largest slopes from 6.7 to 8.3 MAP; however, cultivar differences

Table 1. Field resistance score obtained through a survey and mean time to first symptoms; mean cumulative number of diseased leaves at 12 months after planting (MAP), cubic polynomial equation fitted, largest slope based on fitted cubic polynomial equation and MAP when the largest slope was obtained per replicate (25 plants) for six anthurium cultivars evaluated for resistance/susceptibility to bacterial leaf spot disease caused by Acidovorax anthurii over a 12-month period in a field trial.

\begin{tabular}{|c|c|c|c|c|c|c|c|}
\hline \multirow[b]{2}{*}{ Cultivar } & \multirow[b]{2}{*}{$\begin{array}{l}\text { Field } \\
\text { resistance score }\end{array}$} & \multirow[b]{2}{*}{$\begin{array}{l}\text { MAP to first } \\
\text { symptoms }\end{array}$} & \multicolumn{5}{|c|}{ Mean cumulative diseased leaves per replicate } \\
\hline & & & At 12 MAP & Cubic equation & $R^{2}$ & Largest slope & $\begin{array}{c}\text { MAP for } \\
\text { largest slope }\end{array}$ \\
\hline Acropolis & 3 & 4.3 & 7.3 & $y=-0.0241 x^{3}+0.5148 x^{2}-2.3130 x+2.7298$ & 0.96 & 1.35 & 7.1 \\
\hline Fantasia & 2 & 7.5 & 11.0 & $y=-0.0288 x^{3}+0.6946 x^{2}-3.5190 x+3.8990$ & 0.95 & 2.07 & 8.0 \\
\hline Lambada & 8 & 4.8 & 74.5 & $y=-0.3175 x^{3}+6.0223 x^{2}-22.3160 x+19.003$ & 0.97 & 15.76 & 6.3 \\
\hline Pistache & 5 & 6.0 & 40.8 & $y=-0.1174 x^{3}+2.6869 x^{2}-12.9760 x+13.866$ & 0.96 & 7.52 & 7.6 \\
\hline President & 5 & 4.5 & 64.8 & $y=-0.1440 x^{3}+3.0664 x^{2}-11.6550 x+10.4170$ & 1.00 & 10.11 & 7.1 \\
\hline Sonate & 5 & 3.3 & 28.5 & $y=-0.0680 x^{3}+1.4145 x^{2}-5.7314 x+5.5177$ & 0.98 & 4.08 & 6.9 \\
\hline Significance $(P<)$ & - & NS & 0.001 & - & - & 0.001 & 0.05 \\
\hline Mean & - & 5.0 & 37.8 & - & - & 6.82 & 7.2 \\
\hline SE & - & 1.00 & 3.18 & - & - & 1.388 & 0.65 \\
\hline LSD & - & - & 7.78 & - & - & 3.40 & 1.59 \\
\hline $\mathrm{CV}_{\text {within }}$ & - & 0.40 & 0.17 & - & - & 0.19 & 0.11 \\
\hline $\mathrm{CV}_{\text {between }}$ & - & 0.30 & 0.73 & - & - & 0.81 & 0.08 \\
\hline
\end{tabular}

LSD $=$ least significant difference.

${ }^{\mathrm{z}}$ The smaller the field resistance score, the more resistant was the anthurium cultivar. 
for MAP when the largest slope occurred were not significant. Cultivar differences for largest slope were highly significant $(P<$ $0.001)$ with 'Lambada' having the largest value (3.35), 'Acropolis' (0.37) having the smallest value, and a cultivar mean of 2.05. The largest slope for 'Lambada' was 9-fold that of the largest slope for 'Acropolis'. Tukey-Kramer multiple comparison test placed the anthurium cultivars into two groups based on largest slopes for mean cumulative number of dead plants with Acropolis and Fantasia (0.57) grouping separately from the other anthurium cultivars (2.80).

Association between the parameters. Pearson's product moment correlations (Table 3) for cumulative number of diseased leaves per replicate at 12 MAP with cumulative number of dead plants per replicate at 12 MAP, largest slope for cumulative number of diseased leaves and dead plants per replicate, and field score obtained through the national farm survey ( $r=0.83$ to 0.97$)$ were significant $(P<0.05$ to 0.01$)$. Cumulative number of dead plants per replicate at 12 MAP also showed a significant correlation with largest

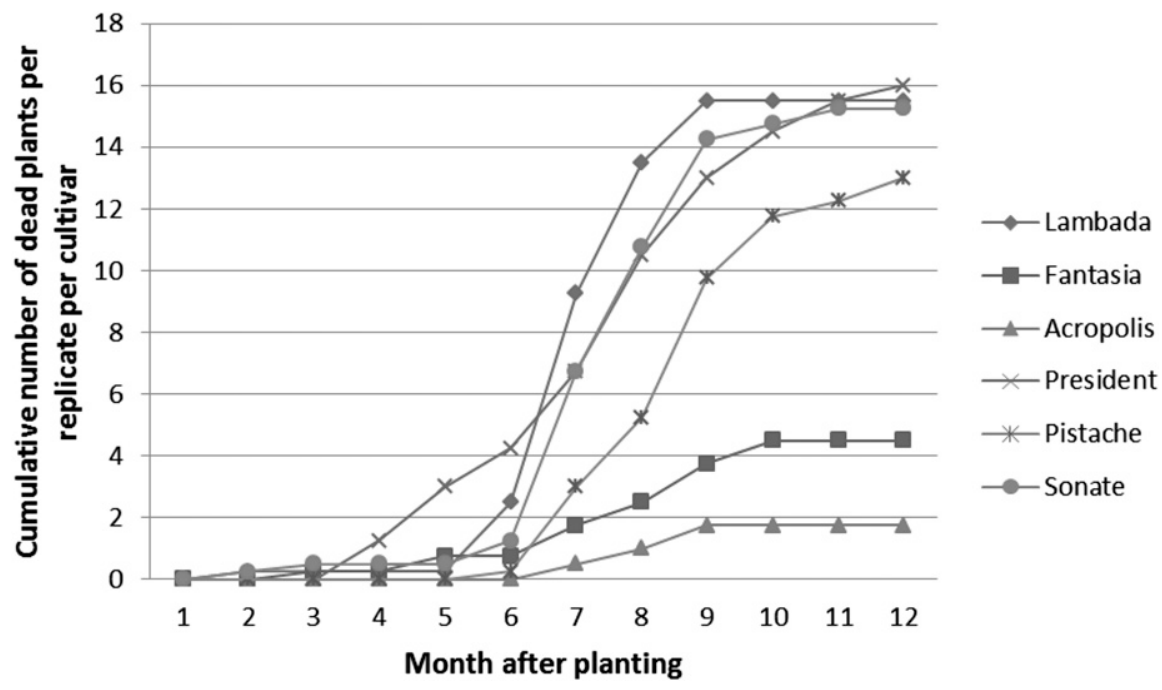

Fig. 2. Cumulative number of dead plants per replicate for six anthurium cultivars observed under field conditions in a bacterial leaf spot disease nursery over a period of 12 months. slope for cumulative number of dead plants per replicate $(r=0.97, P<0.01)$. Field score also showed significant correlations with largest slope for cumulative number of diseased leaves $(r=0.92, P<0.01)$, dead plants per replicate $(r=0.89, P<0.05)$, and MAP when the largest slope occurred $(r=-0.82$, $P<0.05)$. Spearman's rank correlations for cumulative number of diseased leaves per replicate at $12 \mathrm{MAP}$ with cumulative number of dead plants per replicate at 12 MAP $(r=$ $0.89, P<0.05)$ and largest slope for cumulative number of diseased leaves per replicate ( $r=1.00, P<0.001)$ were significant. Also, Spearman's rank correlation between cumulative number of dead plants per replicate at 12 MAP and largest slope for cumulative number of diseased leaves per replicate $(r=$ 0.89 ) was significant at $P<0.05$.

\section{Discussion}

This study shows that BLS progression in six anthurium cultivars as well as cultivar resistance to BLS were reliably discerned under tropical shadehouse conditions in a disease nursery within a 12-month period.
Typical foliar and systemic symptoms associated with BLS (Dilbar, 1992; Holder et al., 2015; Prior and Rott, 1989) were observed over the 12-month period. The study showed that time to first symptoms in the various cultivars occurred without regard to their resistance levels to BLS. However, in 'Acropolis' and the other moderately resistant cultivar, Fantasia, cumulative number of diseased leaves and dead plants per replicate remained low over the duration of the study relative to the four susceptible cultivars.

Acidovorax anthurii can enter anthurium leaves via stomata and hydathodes in contaminated water droplet splashes or through the root system (Prior et al., 1985). Although Prior et al. (1985) and Prior and Sunder (1987) indicated that early symptoms of BLS in anthurium are foliar, which was true for 'Acropolis', 'President', 'Pistache', 'Lambada', and 'Sonate', plant death occurred without visible foliar symptoms in the moderately resistant cultivar, Fantasia. Plant death without foliar symptoms previously has been observed for bacterial blight of anthurium caused by Xanthomonas axonopodis pv. dieffenbachiae in which case the pathogen enters the plant via wounds (Fukui et al., 1998) or through the root system (Prior et al., 1985).

Of the other two measures of resistance studied, progression of cumulative number of diseased leaves over the 12-month period was more discriminatory than number of dead plants over time, although both measures showed a significant correlation $(r=$ $0.84, P<0.05)$. Consequently, the TukeyKramer multiple range test was able to separate the cultivars into four groups for the former compared with only two groups for the latter. Hence cumulative number of diseased leaves per replicate is a better measure than cumulative number of dead plants per replicate for assessing resistance levels to BLS in anthurium.

All the anthurium cultivars showed their largest rate of diseased leaf development from 6.3 to $8.0 \mathrm{MAP}$, with the susceptible cultivars having the exponential growth period earlier than the moderately resistant cultivars. Moreover, the largest slopes during

Table 2. Mean cumulative number of dead plants at 12 month after planting (MAP), cubic polynomial equation fitted, largest slope based on fitted cubic polynomial equation and MAP when the largest slope was obtained per replicate ( 25 plants) for six anthurium cultivars evaluated for resistance/susceptibility to bacterial leaf spot disease caused by Acidovorax anthurii over a 12-month period field trial.

\begin{tabular}{|c|c|c|c|c|c|}
\hline \multirow[b]{2}{*}{ Cultivar } & \multicolumn{5}{|c|}{ Mean cumulative dead plants per replicate } \\
\hline & At 12 MAP & Fitted cubic equation & $R^{2}$ & Largest slope & MAP for largest slope \\
\hline Acropolis & 1.8 & $y=-0.0065 x^{3}+0.1439 x^{2}-0.6946 x+0.7449$ & 0.94 & 0.37 & 7.4 \\
\hline Fantasia & 4.5 & $y=-0.0106 x^{3}+0.2358 x^{2}-0.9919 x+1.0177$ & 0.98 & 0.76 & 7.4 \\
\hline Lambada & 15.5 & $y=-0.0693 x^{3}+1.3964 x^{2}-6.0256 x+5.9924$ & 0.96 & 3.35 & 6.7 \\
\hline Pistache & 13.0 & $y=-0.0281 x^{3}+0.6988 x^{2}-3.5120 x+3.8460$ & 0.97 & 2.28 & 8.3 \\
\hline President & 16.0 & $y=-0.0358 x^{3}+0.7646 x^{2}-2.8849 x+2.5682$ & 0.99 & 2.56 & 7.1 \\
\hline Sonate & 15.3 & $y=-0.0541 x^{3}+1.1516 x^{2}-5.1847 x+5.4343$ & 0.96 & 2.99 & 7.1 \\
\hline Significance $(P<)$ & 0.001 & - & - & 0.001 & NS \\
\hline Mean & 11.0 & - & - & 2.05 & 7.3 \\
\hline SE & 0.70 & - & - & 0.389 & 0.95 \\
\hline LSD & 1.71 & - & - & 0.95 & - \\
\hline $\mathrm{CV}_{\text {within }}$ & 0.13 & - & - & 0.14 & 0.13 \\
\hline $\mathrm{CV}_{\text {between }}$ & 0.57 & 一 & - & 0.59 & 0.07 \\
\hline
\end{tabular}

LSD $=$ least significant difference. 


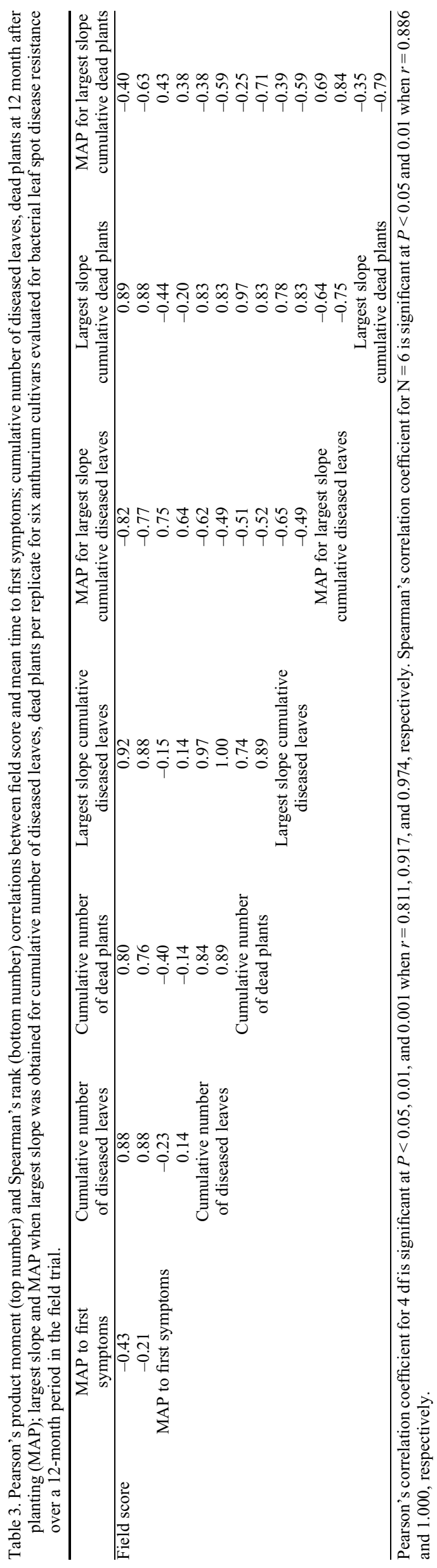

the exponential phase for the susceptible cultivar groups ('Lambada', $15.8 \pm 1.4$; 'President' and 'Pistache', average $8.8 \pm$ 1.4 ; 'Sonate', $4.1 \pm 1.4$ ) were much larger than those for the cultivars that fell into the more resistant categories ('Acropolis' and 'Fantasia', average $1.7 \pm 1.4)$. Dilbar and Gosine (2003) also observed severe foliage symptoms in susceptible cultivars Lambada and President when infected with BLS. At 12 MAP, foliar symptoms of BLS plateaued for all the anthurium cultivars with a similar ranking order as was obtained with the largest slopes during the exponential phase.

All the anthurium cultivars generally had low number of plants $(0.0-4.25)$ per replicate that died from BLS up to 6 MAP, but from 6.7 to 8.3 MAP, they all showed their largest rates of death, with no significant differences among cultivars with regard to the months to reaching the maximum exponential death rate. The maximum death rates during the exponential growth phase were larger for the susceptible cultivars, Lambada, President, Pistache, and Sonate (average $2.8 \pm 0.39$ ) compared with the more resistant cultivars, Acropolis and Fantasia (average $0.57 \pm 0.39$ ). Again, mean cumulative number of dead plants per replicate at 12 MAP was correlated $(r=$ $0.97, P<0.01)$ to the maximum death rates during the exponential growth phase. At that time, the more resistant cultivars, Acropolis and Fantasia showed very low (1.8 to 4.5 plants per replicate) plant death while plant death in the susceptible cultivars ranged from 13 to 16 plants per replicate.

The field rankings from the farm survey study (Holder et al., 2015) showed a strong correlation with cumulative number of diseased leaves per replicate at 12 MAP, the maximum slope for the exponential phase for cumulative number of diseased leaves per replicate at $12 \mathrm{MAP}$, and months to reach the maximum slope indicating a strong concordance between the collective wisdom of farmers and the field screening study. This provides validity to the results obtained from this study.

Although 'Pistache' and 'Sonate' were designated as being susceptible to BLS based on the farm survey, 'Pistache' did not develop foliar symptoms until 5 MAP and 'Sonate' had a relatively low cumulative number of diseased leaves per replicate at 12 MAP. This may suggest that 'Pistache' and 'Sonate' were able to harbor the pathogen without symptom development for some time. Latent infection has been reported for the bacterial blight pathogen ( $X$. axonopodis pv. dieffenbachiae) in anthurium (Alvarez et al., 1991; Fernandez et al., 1991) and it is well known that plants infected with bacterial blight disease can exude guttation fluid containing the pathogen, which can infect adjacent plants (Fukui et al., 1999; Norman and Alvarez, 1996). The same may hold true for latent infection of anthurium with $A$. anthurii. 
In conclusion, this field study showed that assessment of resistance levels of anthurium cultivars to BLS under disease nursery conditions can be reliably used in breeding to identify reliable resistance/tolerance to BLS symptom development over a 12-month period. Time to symptom development was found to be independent of a cultivar's resistance level to BLS. Although cumulative number of diseased leaves and dead plants generally plateaued at 12 MAP and were correlated with each other, the former was more discriminatory than the latter and is therefore recommended to be used as a measure of field resistance. The strong correlation between the rate of diseased leaf increase during the exponential growth phase and the final diseased leaf count at 12 MAP shows firstly that resistance/tolerance to the disease is a function of the ability to retard the building of epiphytotics and secondly that the cumulative number of diseased leaves at 12 MAP can be used as a simple measure of resistance to BLS. The study has also identified two anthurium cultivars (Acropolis and Fantasia) as possessing useful levels of resistance to BLS and recommends that more studies should be done to understand the mechanism of resistance and tolerance to BLS.

\section{Literature Cited}

Alvarez, A.M., D. Norman, and R. Lipp. 1991. Epidemiology and control of anthurium blight, p. 12-18. In: A.M. Alvarez, D.C. Deardorff, and K.B. Wadsworth (eds.). Proc. 4th Hawail Anthurium Ind. Conf. HITAHR (Hawaii Inst. Trop. Agr. Human Resources) J. Ser. 04.06.91.

Dilbar, A. 1992. Studies on a new bacterial disease and other diseases of anthurium in Trinidad. M. Sc. Diss., Univ. of West Indies, St. Augustine, Trinidad.

Dilbar, A. and G. Gosine. 2003. Evaluation of susceptibility of anthurium hybrids to pseudomonas blight (Acidovorax anthurii sp.) and anthurium bacterial blight (Xanthomonas campestris pv. dieffenbachiae). CARAPHIN, IICA 23:4-6.

Fernandez, J.A., A. Alvarez, P. Moriyasu, and D. Norman. 1991. Certification and indexing of anthurium, p. 10-11. In: A.M. Alvarez, D.C. Deardorff, and K.B. Wadsworth (eds.). Proc. 4th Hawaii Anthurium Ind. Conf. HITAHR (Hawaii Inst. Trop. Agr. Human Resources) J. Ser. 04.06.91.

Fukui, H., A.M. Alvarez, and R. Fukui. 1998. Differential susceptibility of anthurium cultivars to bacterial blight in foliar and systemic infection phases. Plant Dis. 82:800-806.

Fukui, R., H. Fukui, and A.M. Alvarez. 1999. Effect of temperature on the incubation period and leaf colonization in bacterial blight of anthurium. Phytopathol. 89:1007-1014.
Gardan, L., C. Dauga, P. Prior, M. Gillis, and G.S Saddler. 2000. Acidovorax anthurii sp. nov., a new phytopathogenic bacterium which causes bacterial leaf-spot of anthurium. Intl. J. Syst. Evol. Microbiol. 50:235-246.

Holder, A.W.B., W. Elibox, and P. Umaharan. 2015. Status of bacterial leaf spot disease of Anthurium in Trinidad and characterization of native isolates of the causal organism, Acidovorax anthurii. HortScience 50:1023-1027.

NCSS. 2007. Number crunching statistical system. NCSS, Kaysville, UT.

Norman, D.J. and A.M. Alvarez. 1996. Monitoring the spread of Xanthomonas campestris pv. dieffenbachiae introduced from symptomless anthurium cuttings into production fields. J. Amer. Soc. Hort. Sci. 121:582-585.

Prior, P., B. Hostachy, P. Sunder, and P. Rott. 1985. Bacterial blight $(X$. campestris pv. dieffenbachiae) and bacterial leaf spot (Pseudomonas sp.) of anthurium in the French West Indies. Agron. Trop. 42:61-68.

Prior, P. and P. Rott. 1989. Bacterial leaf spot of anthurium (Anthurium spp.) caused by a Pseudomonas sp. in the French West Indies. J. Phytopathol. 124:215-224.

Prior, P. and P. Sunder. 1987. Les maladies bacteriennes de l'anthurium. P.H.M. Rev. Hort. 277.

Saddler, G.S., E.B. O'Grady, and J.A. Spence. 1995. Characterization of a pseudomonad-like bacterium pathogenic for Anthurium species. EPPO Bul. 25:211-217. 